\title{
Racionalidade, incomensurabilidade e história: um diálogo entre as obras de Herbert Simon e Thomas Kuhn
}

Rationality, incommensurability and history: a dialogue between the works of Herbert Simon and Thomas Kuhn

João Luiz Pondé

Universidade Federal do Rio de Janeiro

\section{Abstract}

The paper offers a comparative discussion of the rationality conceptions which are found in the works of Herbert Simon and Thomas Kuhn. Both authors oppose to formal concepts of rationality, that associate rational choice to some kind of abstract and universal algorithm and reduce the decision process to a set of logical operations. To build an alternative, Simon and Kuhn develop rationality notions that can be applied to ill structured decisions problems, in the sense that decision makers cannot deductively infer a unique action from the parameters of the decision problems. In this way, rational choices involve options that are incommensurable, but not incomparable. Although there are differences in their approaches, Simon and Kuhn take a similar stance and propose rationality concepts in which (i) the rationality of beliefs, choices and behavior are embedded in specific activities and social practices, and (ii) these activities and practices evolve in historical time.

\section{Keywords}

rationality; incommensurability; rational choice; theory choice; bounded rationality.

JEL Codes B41; A12; D01.

\section{Resumo}

O artigo oferece uma discussão comparativa das concepções de racionalidade encontradas nas obras de Herbert Simon e Thomas Kuhn. Ambos os autores se contrapõem a concepções formais da racionalidade, que associam a escolha racional a algum algoritmo abstrato e universal, reduzindo o processo de decisão a um conjunto de operações lógicas. Como alternativa, Simon e Kuhn desenvolvem noções de racionalidade aplicáveis a situações decisórias mal estruturadas, no sentido de que os tomadores de decisão não conseguem inferir dedutivamente uma única linha de ação a partir dos parâmetros dos problemas decisórios. Deste modo, as escolhas racionais envolvem opções que são incomensuráveis, mas não incomparáveis. Embora existam diferenças entre suas abordagens, Simon e Kuhn assumem uma postura similar ao proporem conceitos de racionalidades nos quais (i) a racionalidade das crenças, escolhas e comportamentos está assentada em atividades e práticas sociais especificas, e (ii) essas atividades e práticas evoluem no tempo histórico.

\section{Palavras-chave}

racionalidade; incomensurabilidade; escolha racional; escolha teórica; racionalidade limitada.

Códigos JEL B41; A12; D01. 


\section{Introdução}

O objetivo deste artigo é explorar oportunidades de estabelecer um diálogo entre as obras de Herbert Simon e Thomas Kuhn, identificando convergências e divergências, aproximações e afastamentos, em suas concepções de racionalidade e escolha racional. Não se pretende buscar algum tipo de integração teórica ou mesmo delinear uma possível metateoria da escolha racional, mas sim refletir acerca dos desafios enfrentados no desenvolvimento de abordagens teóricas da racionalidade quando se admite que esta seja o produto da interação humana no tempo histórico, e não a manifestação de uma lógica das decisões universal e válida a priori. Como veremos a seguir, os dois autores chegam, por diferentes caminhos, a uma postura empírica e histórica diante da questão da racionalidade das decisões, oferecendo lições importantes para economistas e outros cientistas sociais. Cabe notar que não se trata de um diálogo encontrado nas obras dos autores, mas estabelecido a partir delas. Até onde fui capaz de verificar, não há qualquer referência a Simon nos escritos de Kuhn e as citações feitas a Estrutura das Revoluções Científicas em textos de Simon são poucas, não indicando uma influência relevante. ${ }^{1}$

Tal modalidade de reflexão, ultrapassando as fronteiras disciplinares da Economia e trazendo para a discussão abordagens originalmente restritas à Filosofia da Ciência, não é certamente inédita. Há mais de duas décadas, Loasby $(1986,1989)$ já sugeria que há muito a aprender a partir de um diálogo entre a teoria econômica (heterodoxa) e a filosofia da ciência contemporânea, já que ambas compartilham a preocupação em investigar e compreender a expansão do conhecimento - seja este o conhecimento produtivo nas firmas ou o conhecimento científico. As semelhanças entre as decisões dos agentes econômicos em condições de racionalidade limitada, com a presença de incerteza, e as escolhas dos cientistas entre paradigmas alternativos, nas revoluções científicas, são discutidas por Cunha (2005). Por sua vez, De Langhe $(2012,2013)$ argumenta que as dificuldades enfrentadas por Kuhn em caracterizar a escolha teórica como racional seriam superadas se as decisões dos cientistas forem analisadas a partir dos mo$1 \mathrm{Na}$ verdade, Simon sofreu uma influência duradoura do positivismo de Rudolf Carnap ainda no início de sua formação acadêmica, especialmente no que se refere ao papel da indução na ciência e à distinção entre fato e valor (Miller, 2008, p. 937-938). Não estou supondo, portanto, que Simon e Kuhn apresentem qualquer tipo de convergência no que se refere a suas concepções gerais acerca do processo de desenvolvimento científico. 
delos de satisficing desenvolvidos por Simon. Minha abordagem também envolve a busca de similaridades ou pontos de aproximação entre Simon e Kuhn, mas sem pressupor que haja um ganho significativo a ser auferido na aplicação de ideias de um aos problemas específicos que são discutidos por outro - como alternativa, procuro desenvolver um estudo comparativo que permita identificar como ambos enfrentam, de forma semelhante, a necessidade de reformular os conceitos de racionalidade recebidos de seus predecessores. Neste esforço, a noção kuhniana de incomensurabilidade tem um papel decisivo, como ficará evidente ao longo do texto.

A pertinência de tal estudo comparativo poderia ser posta em questão, a partir da ponderação de que o conceito de racionalidade é abordado a partir de diferentes perspectivas nas ciências sociais e na filosofia da ciência - tal como esta última era predominantemente concebida até algumas décadas atrás. Nas ciências sociais, a noção de racionalidade usualmente adotada envolve a formulação de hipóteses sobre o comportamento de indivíduos e grupos de indivíduos em uma ampla variedade de arranjos institucionais a serem avaliados por sua capacidade de descrever, explicar e/ou prever ações e padrões de interação social - trata-se da racionalidade do tomador de decisões. Por sua vez, a filosofia da ciência - como desenvolvida, por exemplo, pelos positivistas ou pelos popperianos - aborda a questão da racionalidade a partir de uma análise lógica e conceitual, procurando estabelecer a priori as condições que tornam racionalmente justificada a aceitação de crenças e teorias, com base em critérios intersubjetivos de racionalidade. Desse ponto de vista, as discussões de Simon e Kuhn sobre a questão da racionalidade estariam contidas em campos intelectuais distintos: a primeira em torno de um conceito de racionalidade instrumental, a segunda em torno de um conceito categórico de racionalidade, dentro de um projeto clarificação dos fundamentos do conhecimento.

No entanto, o desenvolvimento recente da filosofia da ciência e da epistemologia apresenta iniciativas relevantes que rompem com tal divisão, especialmente a partir da emergência de abordagens denominadas naturalistas - ver, por exemplo, Giere (1988, 2008), Kitcher (1992) e Abrantes (1993). Embora exista relativa diversidade entre os articuladores de uma perspectiva naturalista na filosofia da ciência, o ponto em comum entre eles está na rejeição de metametodologias baseadas em análise a priori e a consequente afirmação de uma continuidade entre a filosofia ciência e a próprio conhecimento científico, de maneira que o estudo da ciência se 
torna, ele mesmo, um empreendimento científico. Isso implica reinterpretar as questões tradicionais da filosofia da ciência, substituindo a análise lógica e conceitual por perspectivas científicas e empíricas - oriundas, por exemplo, da psicologia, das ciências cognitivas, da sociologia ou do darwinismo. Quando preservam um interesse em questões relacionadas à racionalidade científica, os naturalistas adotam a noção de racionalidade instrumental (Giere, 1989; Laudan, 1990), incorporando modelos teóricos que permitam descrever e explicar os processos decisórios dos cientistas, incluindo modelos de racionalidade limitada inspirados em Simon (Giere, 1988, p. 157-64). ${ }^{2}$

Situada numa perspectiva naturalista, a obra de Kuhn revela alguns de seus aspectos mais originais frente à filosofia da ciência da sua época, o que inclui sua discussão da racionalidade científica (Rouse, 2013). ${ }^{3}$ Assumindo que "a avaliação de critérios para a escolha de teorias requer a especificação prévia dos objetivos a serem escolhidos por esta escolha", Kuhn (1983b, p. 256) prossegue apontando que a racionalidade das escolhas dos cientistas está justamente em avaliar as teorias a partir de características que garantam um aumento de sua capacidade de resolução de quebra-cabeças - e se exime de buscar uma justificativa (filosófica) para além da eficácia instrumental das normas de decisão que guiam a prática científica (Wray, 2011, p. 68-9). Desse modo, é predominantemente no campo da racionalidade instrumental que um diálogo entre Simon e Kuhn pode ser travado, ainda que os arranjos institucionais da ciência e do sistema econômico (mercados, organizações empresariais) apresentem diferenças importantes, notadamente no que tange a como os tomadores de decisões se inserem em relações de cooperação, competição e autoridade, ensejando diferentes articulações entre decisões individuas e padrões coletivos de comportamento.

O artigo está organizado em seis seções, incluindo esta introdução. Nas seções 2 e 3, são apresentadas, respectivamente, a teoria da racionalidade procedimental de Simon e a argumentação de Kuhn acerca da escolha entre paradigmas, durante o desenrolar das revoluções científicas. Na seção 4,

2 O naturalismo não implica necessariamente o abandono de um projeto normativo na filosofia da ciência, mas concede às normas de racionalidade um novo estatuto: são provisórias, justificadas pelos resultados observados e podem ser revistas com a experiência (Laudan, 1990).

3 O reconhecido viés naturalista da obra de Kuhn se expressa nitidamente em seus embates com Popper, nos quais o confronto com a posição antinaturalista deste último ajuda a explicar as dificuldades de comunicação entre os dois autores (Abrantes, 1993, p. 196-8). 
um alinhamento das similaridades entre os autores é utilizado para argumentar que suas contribuições mais duradouras têm um elemento em comum: uma reconstrução do conceito de racionalidade, que pode ser caracterizado como um movimento de abandono de uma noção puramente formal de escolha racional, em direção a uma concepção social, plural e histórica. Na seção 5, são identificadas duas diferenças fundamentais entre suas abordagens, estabelecendo limites para tentativas de integrá-las em uma perspectiva unificada. Por fim, a seção 6 comenta, de forma concisa, os resultados da reflexão realizada.

\section{Simon: racionalidade procedimental e aprendizado}

Herbert A. Simon dedicou sua longa carreira acadêmica à construção de uma teoria das decisões cujo mote central, que se manifesta em uma variedade de contribuições em diferentes disciplinas, é o respeito às condições reais nas quais os agentes tomam decisões - caracterizadas como condições de racionalidade limitada. Os "limites" à racionalidade decorrem de características tanto do tomador de decisões quanto do ambiente em que este se encontra, incluindo assim: (i) limites cognitivos de indivíduos e organizações, que possuem sempre uma capacidade limitada de coletar, processar e interpretar informações; (ii) a complexidade do problema decisório com o qual o agente relevante se defronta, resultante de atuar em uma ambiente cujas relações causais e regularidades são difíceis de serem discernidas; e (iii) a incerteza em relação a eventos exógenos. Na presença de tais condições, uma teoria das decisões deve desenvolver modelos nos quais se reconheça explicitamente que:

Alternativas de busca devem ser procuradas, as consequências de escolher uma alternativa particular são conhecidas apenas de forma muito imperfeita, devido tanto a limites no poder computacional quanto devido à incerteza do mundo externo, e o tomador de decisões não possui uma função de utilidade geral e consistente para comparar alternativas heterogêneas. (Simon, 1979, p. 501). ${ }^{4}$

A presença de limites cognitivos e complexidade implica que o tomador de decisões enfrenta um gap de competências, resultando no que Dosi e Egidi (1991) caracterizam como incerteza procedimental (procedural) uma falta de conhecimento que decorre da incapacidade dos agentes de

4 Um limite adicional pode resultar da incapacidade dos tomadores de decisão em ordenarem suas preferências de forma clara e completa, como reconhecido em Simon (1955, p 108-9). 
mapear e explorar todo o leque de alternativas disponível para a escolha. ${ }^{5}$ Por outro lado, o fato de Simon não fazer mais que uma referência casual à incerteza que emerge do ambiente (os "eventos exógenos"), bem como sua recorrente preocupação em analisar situações decisórias caracterizadas por uma estrutura bem definida e dada, como no jogo de xadrez, tem levado alguns críticos a limitar suas contribuições ao estudo de consequências das limitações computacionais, considerando-as inapropriadas para situações de mudança endógena, incerteza substantiva forte e criatividade (Loasby, 1989; Dequech, 1991; Augier; Kreine, 2000).

Entretanto, o próprio Simon caracteriza sua teoria do comportamento racional como voltada para problemas decisórios nos quais os indivíduos não só pensam, como também inventam (Simon, 1976, p. 84), ou a ambientes que mudam rapidamente (Simon, 1959, p. 279). ${ }^{6}$ Além disso, os modelos de tomada de decisões em condições de racionalidade limitada são invariavelmente apresentados como alternativas a modelos de maximização da utilidade esperada, que Simon enfaticamente critica por irrealisticamente suporem que os agentes possuem as informações necessárias para a realização de cálculos probabilísticos acerca de eventos futuros. ${ }^{7}$ Mas o argumento mais decisivo talvez seja a existência de uma importante literatura que se utiliza da abordagem proposta por Simon para desenvolver modelos dinâmicos, voltados explicitamente para a investigação das decisões e interações entre agentes em ambientes econômicos marcados pela presença de inovação e incerteza substantiva forte (Dosi, 2004; Nelson, 2011). Sob este ponto de vista, o legado de Simon deve ser buscado não apenas nos modelos específicos que ele desenvolveu, que por si só são insuficientes para tratar adequadamente a grande diversidade de processos cognitivos

5 Dosi e Egidi (1991) desenvolvem a distinção entre incerteza substantiva e incerteza procedimental "em analogia à distinção de $\mathrm{H}$. Simon entre racionalidade 'substantiva' e racionalidade procedimental'" (p. 146). A incerteza substantiva está associada a algum tipo de ausência de informação sobre eventos que afetam o resultado das decisões, enquanto a incerteza procedimental decorre de um gap de competência na atividade de resolução de problemas.

6 Ver também Simon (1983), que discute elementos de uma abordagem que se propõe a tratar o pensamento criativo, baseada em regras heurísticas e processos de tentativa-e-erro.

7 Ao discutir a formação de expectativas em condições de racionalidade limitada, Simon (1959) defende a relevância do que ele chama de naïve models, nos quais os agentes supõem que o futuro será igual ao presente, que o próximo período diferirá do presente da mesma maneira que este difere do último período passado, ou que o futuro será igual a uma média ponderada de períodos passados - procedimentos de formação de expectativas similares ao comportamento convencional da tradição keynesiana (Keynes, 1936, Cap. 12; Possas, 2002, p. 133-6). Simon destaca que "existe alguma evidência positiva de que as previsões empresariais se ajustam a estes modelos" (p. 269). 
envolvidos nas escolhas (Dosi et al., 2005), mas na perspectiva geral dos mecanismos decisórios por ele oferecida, capaz de acomodar uma ampla variedade adicional de modelos de processos racionais de decisão e aprendizado, assumindo diferentes combinações de incerteza procedimental e incerteza substantiva forte (Dosi; Egidi, 1991; Rizello, 2002). ${ }^{8}$

Se o reconhecimento da presença da racionalidade limitada leva Simon a abandonar modelos teóricos que definem a escolha racional como a maximização de uma função-objetivo bem definida, a construção de uma alternativa factível o conduz a admitir que os agentes tomarão decisões baseados em um montante de informações que não é ótimo, em expectativas ou crenças que não são inteiramente justificadas de forma racional e utilizando critérios de escolha que não realizam uma comparação exaustiva de todas as alternativas possíveis. Trata-se da substituição de uma teoria da racionalidade substantiva - que define a conduta racional como aquela que gera um determinado resultado, caracterizado como ótimo - por uma teoria da racionalidade procedimental, na qual o caráter racional das decisões decorre das propriedades do processo de escolha, que permitem caracterizar a decisão como envolvendo uma deliberação apropriada (Simon, 1976). ${ }^{9}$

Sendo assim, a teoria de Simon é uma teoria dos procedimentos racionais de decisão, cuja construção se faz a partir de uma contínua interação entre a generalização teórica e a investigação empírica (Barros, 2010). Os processos decisórios são, então, concebidos como contendo uma ampla e variada gama de estratégias, rotinas, regras heurísticas e convenções que podem ser agrupadas em três componentes básicos:

i. Procedimentos de busca e avaliação de alternativas, a partir dos quais os agentes geram representações do ambiente em que operam, produzem endogenamente o leque de alternativas a ser considerado no

8 Para uma discussão de como as contribuições de Simon são especialmente relevantes para os microfundamentos de uma abordagem teórica que combina elementos schumpeterianos $e$ keynesianos, e que, portanto, tem como elementos centrais a incerteza, a criatividade e a inovação, ver: Possas (2002).

9 Um "comportamento é racional no sentido procedimental quando é o resultado de uma deliberação apropriada. Sua racionalidade procedimental depende do processo que o gerou" (Simon, 1976, p. 68). Neste caso, o comportamento é julgado racional pelos procedimentos que emprega nas decisões, e não pelas escolhas que elas geram. Por sua vez, um "comportamento é racional no sentido substantivo quando é apropriado para o alcance de objetivos dados, dentro dos limites impostos por estes ou por restrições" (Simon, 1976, p. 67) - neste caso, uma vez especificado o objetivo do tomador de decisões, seu comportamento é totalmente determinado pelo ambiente. 
processo decisório e avaliam suas consequências. Como destaca Simon (1955), os procedimentos de busca possuem três características básicas: (a) envolvem processos cognitivos específicos, que são responsáveis por construir uma "representação do problema decisório"; (b) são seletivos, levando a uma exploração parcial e, em certo sentido, idiossincrática das características e oportunidades exógenas do ambiente; e (c) são adotados por terem se provado bem-sucedidos no passado. Ou seja, o leque de alternativas a partir do qual a escolha se dá não é um dado exógeno, mas sim construído pelo próprio processo de decisão, a partir de um conjunto de atos cognitivos.10

ii. Procedimentos de seleção da alternativa a ser escolhida, que envolvem a definição das submetas a partir das quais os resultados de cada alternativa são avaliados, e do nível de aspiração associado a cada submeta, que atua como o gatilho que desencadeia a escolha da alternativa considerada satisfatória - mecanismo caracterizado como satisficing.11 A necessidade de definição das submetas resulta do fato de não se supor que o tomador de decisões possui uma função-objetivo completa e consistente, capaz de ordenar todo e qualquer par de alternativas a partir de seu impacto estimado sobre a meta global do indivíduo ou da organização - utilidade ou lucro, respectivamente.12 Por sua vez, o mecanismo do satisficing é compatível com uma situação na qual o agente deve escolher a partir de múltiplos objetivos, sem ser capaz de estimar precisamente eventuais trade-offs entre objetivos.

iii. Mecanismos de aprendizado e adaptação, uma vez que, ao longo do tempo, existem relações de feedback entre os resultados das decisões e os procedimentos decisórios, levando a modificações nas estratégias

10 O decisivo nos procedimentos de busca não é, por conseguinte, a quantidade de busca a ser realizada (como, por exemplo, em Stigler, 1961), mas o tipo e a forma da busca.

11 A noção de escolha satisfatória é introduzida por Simon (1955, p. 104) através da definição de uma matriz de pay-offs que classifica as alternativas a serem escolhidas em "satisfatórias" e "insatisfatórias", a partir da definição de um conjunto de submetas. Ver também Simon (1959, p. 262-4) e Simon (1979, p. 502-3) para uma apresentação do satisficing como a base de uma alternativa aos modelos que pressupõem o comportamento maximizador.

12 No caso das firmas, Simon (1979, p. 500) aponta que a definição de submetas ocorre sempre que "os objetivos da organização não podem ser operacionalmente conectados com as ações (a função de produção não pode ser formulada em termos concretos)", de modo que as decisões acabam tendo que se avaliadas a partir de metas secundárias, subordinadas à meta global. Dado que "não há uma única determinação [possível] de submetas", esta determinação dependerá da configuração específica do conhecimento, experiência e ambiente organizacional do tomador de decisão. 
de busca, níveis de aspiração ou definição de submetas (Simon, 1955, p. 113; Simon, 1979, p. 510; Simon, 1976, p. 82-84). Deste modo, os agentes vão dinamicamente alterando os parâmetros dos processos decisórios a partir de suas interações com o ambiente.

Ao deslocar a definição do comportamento racional para o processo de decisão, a abordagem de Simon tem uma implicação importante: as escolhas deixam de ser caracterizadas a partir de um conjunto de regras lógicas abstratas para serem tratadas como atividades, sequências de ações sociais que consomem recursos, exigem capacitações específicas para o seu desempenho e - no caso das firmas - estão associadas a formas de dividir e organizar tarefas entre indivíduos e grupos de indivíduos, coordenando seu trabalho por meio de uma estrutura de comunicações e relações de autoridade. Daí a conclusão de que

As elaboradas organizações que, no mundo moderno, os seres humanos têm construído para levar a cabo as atividades de produção e gestão devem ser entendidas como uma maquinaria para lidar com os limites das habilidades humanas em computar e compreender diante da complexidade e da incerteza. (Simon, 1979, p. 501). ${ }^{13}$

Esta diluição da distinção entre "decidir" e "fazer" tem uma importância fundamental no desenvolvimento da teoria neo-schumpeteriana da firma, a partir da noção de "rotinas organizacionais" (Nelson; Winter, 1982; Winter, 2006).

Os processos decisórios dependem, então, de características internas e específicas do tomador de decisões, o que gera necessariamente uma diversidade comportamental nos mercados. Tal diversidade é preservada e continuamente realimentada pelos processos de aprendizado intrínsecos à racionalidade procedimental, o que tem duas implicações importantes. A primeira é o reconhecimento teórico que as decisões são tomadas em desequilíbrio, em um contexto no qual o aprendizado se dá na forma de uma evolução dos procedimentos utilizados pelo tomador de decisões.

13 Embora a preocupação de Simon seja, invariavelmente, a descrição e análise das atividades desempenhadas especificamente nos processos decisórios, ele também destaca a importância de levar em conta as "influências sociais sobre a escolha, que determinam o papel do ator. Nestes termos, um papel é uma prescrição de algumas, mas não todas, das premissas que atuam no comportamento de escolha do indivíduo. (...) Dentro desta estrutura [que leva em conta tanto os papéis como os elementos individuais e idiossincráticos das decisões], podemos acomodar tanto os elementos racionais da escolha, tão enfatizados pelos economistas, como os elementos não racionais, para os quais os psicólogos e sociólogos frequentemente preferem chamar a atenção (Simon, 1959, p. 274). 
A segunda é que, como o resultado deste aprendizado se caracteriza pela presença de dependência de caminho (Rizello, 2002, p. 12), os principais parâmetros dos processos de decisão em um período $t$ qualquer - procedimentos de busca, heurísticas e níveis de aspiração - "dependem da história prévia do sistema" (Simon, 1955, p. 113). ${ }^{14}$

Logo, adotar a teoria da racionalidade no procedimento implica reconhecer que os processos racionais de decisão se caracterizam por envolverem atividades e práticas sociais que podem ser organizadas de diferentes formas e evoluem no tempo histórico. Herbert Simon oferece uma abordagem na qual uma classe ampla de decisões e comportamentos, mesmo sob incerteza e complexidade, pode ser caracterizada como racional, desde que se verifique a presença de intencionalidade nas ações observadas e uma razão instrumental que conecta meios a fins, na medida em que um feedback entre decisões e resultados estabelece um mecanismo de correção de rumos diante de resultados insatisfatórios. Este feedback, por sua vez, desencadeia um processo pelo qual o agente avalia criticamente os procedimentos em uso e os altera quando julga necessário, de maneira que um processo de aprendizado torna os procedimentos em uso um resultado da história de decisões e interações com o ambiente por ele vivenciado. ${ }^{15}$ Por isso, Vanberg (1993, p. 179) conclui que a racionalidade procedimental "é em essência uma teoria do aprendizado comportamental, uma teoria que procura compreender o comportamento corrente de uma pessoa em termos da sua experiência passada".

\section{Kuhn: valores compartilhados e a racionalidade da escolha teórica}

A obra de Thomas S. Kuhn, em especial o livro A estrutura das revoluções científicas, publicado originalmente em 1962, marcou decisivamente o debate contemporâneo sobre a racionalidade científica, seja por dar um impulso

14 Para Vanberg (1993), Simon "sugere uma teoria da tomada de decisões humana que vê o comportamento de escolha de um ator como baseado em um repertório de padrões comportamentais, rotinas ou programas. O repertório reflete, em qualquer momento do tempo, a experiência passada do ator e é, através da tentativa-e-erro, continuamente ajustado à medida que novas experiências são vividas" (p. 180).

15 Como enfatiza Simon (1978, p. 8), "o aprendizado, na forma da reação às consequências percebidas, é o modo dominante pelo qual a racionalidade se manifesta". 
importante na crítica e abandono da perspectiva positivista, por influenciar os desenvolvimentos subsequentes, ou desencadear controvérsias que têm mostrado notável poder de persistência. ${ }^{16}$ Os argumentos mais inovadores - e polêmicos - de Kuhn sobre este tópico estão concentrados nos capítulos 10 e 12 de $A$ estrutura..., ${ }^{17}$ nos quais se discute a forma como, em uma revolução científica, o paradigma até então dominante é substituído por um paradigma novo e alternativo, alterando substancialmente as teorias, compromissos metodológicos e pressupostos ontológicos da comunidade científica e dando origem a uma nova ciência normal, incompatível com a anterior.

De acordo com Kuhn, as análises históricas dos episódios de revoluções científicas mostram que "as diferenças entre paradigmas sucessivos são ao mesmo tempo necessárias e irreconciliáveis" (1987, p. 137), dado que: (i) existem diferenças em relação ao que cada paradigma ensina sobre "a população do universo e sobre o comportamento dessa população", de maneira que cada paradigma verá o mundo como composto por diferentes tipos de entidades; e (ii) existem diferenças quanto aos métodos, áreas problemáticas e padrões de solução aceitos pela comunidade científica (ou seja, diferenças quanto aos problemas e às formas aceitáveis de resolvê-los). Por isso, "a recepção de um novo paradigma requer com frequência uma redefinição da ciência correspondente” (p. 138), já que cada paradigma considerará diferentes tipos de questões como significativas e terá diferentes padrões de avaliação da solução de problemas científicos. ${ }^{18}$ Daí a conclusão de que "a tradição científica normal que emerge de uma revolu-

16 Este debate reflete um ponto de ruptura no desenvolvimento da filosofia da ciência, modificando suas relações com a história e a sociologia da ciência. Nas palavras de Hacking (1983, p. 1): "Por um longo tempo os filósofos fizeram da ciência uma múmia. Quando finalmente eles desembrulharam o cadáver e viram os restos de um processo histórico de descoberta e transformação, eles criaram para si uma crise da racionalidade. Isso aconteceu por volta de 1960".

$17 \mathrm{Na}$ tradução brasileira, os capítulos recebem os números 9 e 11, dado que a Introdução não foi numerada.

18 Os itens (i) e (ii) acima podem ser melhor entendidos se assumirmos que os paradigmas têm uma função cognitiva e uma função normativa. Os paradigmas, na sua função cognitiva, seriam como um "mapa" que indica aos cientistas "que entidades a natureza contém ou não contém, bem como as maneiras segundo as quais estas entidades se comportam" (Kuhn, 1987, p. 143). Os detalhes deste mapa são elucidados pela ciência normal, e sua presença é essencial para que os cientistas possam explorar sistematicamente a natureza. Na sua função normativa, os paradigmas forneceriam "algumas indicações essenciais para a elaboração de mapas. Ao aprender o paradigma, o cientista adquire ao mesmo tempo uma teoria, métodos e padrões científicos, que usualmente compõem uma mistura inextrincável. Por isso, quando os paradigmas mudam, ocorrem alterações significativas nos critérios que determinam a legitimidade, tanto dos problemas, como das soluções propostas" (p. 144). 
ção científica é não somente incompatível, mas muitas vezes verdadeiramente incomensurável com aquela que a precedeu" (p. 138) - a conhecida, e controversa, tese da incomensurabilidade.

Percebe-se, assim, que a incomensurabilidade dos paradigmas, bem como seus desdobramentos para a análise das decisões dos cientistas, possui dois aspectos distintos, ainda que interdependentes. De um lado, tendo abandonado a noção de uma linguagem observacional neutra, que permita referir a comparação de paradigmas alternativos a um conjunto fixo e absoluto de dados observacionais, Kuhn dá um passo adiante e propõe que paradigmas alternativos apresentam "descontinuidades entre suas ontologias" (McMullin, 1993, p. 70), afirmando que os defensores de paradigmas distintos "praticam seus ofícios em mundos diferentes" (Kuhn, 1987, p. 190). De outro, Kuhn enfaticamente recusa a noção de que a racionalidade da escolha entre paradigmas possa estar assentada em um conjunto de regras metodológicas a priori e universais, que determinam a superioridade de um paradigma com a força de uma demonstração lógica - regras que configurariam o que a filosofia da ciência tradicionalmente denominava de Método Científico. Esses dois aspectos levam vários comentadores a adotar a distinção entre dois tipos de incomensurabilidade: a semântica (ou conceitual) e a metodológica. ${ }^{19}$

O resultado $\mathrm{da}(\mathrm{s})$ incomensurabilidade(s) é que a escolha teórica não pode mais ser concebida como determinada pela lógica e pela observação neutra da natureza. A escolha entre paradigmas, assinala Kuhn, seria rotineira "se houvesse apenas um conjunto de problemas científicos, um único mundo no qual ocupar-se deles e um único conjunto de padrões científicos para a sua solução" (1970a, p. 187). Neste caso, bastaria empregar "algum processo como o de contar o número de problemas resolvidos por cada um deles" (1970a, p. 187). Mas isso não ocorre - quando os paradigmas estão em competição, "nenhuma das partes aceitará os pressupostos não empíri-

19 A incomensurabilidade semântica envolve diferenças nos significados de conceitos-chave de tradições teóricas alternativas, que geram dificuldades na comunicação entre os cientistas e fazem com que as incompatibilidades entre teorias não possam ser reduzidas a uma simples contradição lógica - a inexistência de um vocabulário compartilhado e semanticamente neutro impede que asserções sobre o mundo feitas por uma teoria sejam comparadas logicamente com as proposições de outra teoria. Já a incomensurabilidade metodológica envolve uma incompatibilidade entre as normas que guiam as práticas científicas em tradições teóricas alternativas, de maneira que cada grupo de cientistas aplica critérios distintos para guiar suas decisões e avaliar sua prática, o que implica a inexistência de padrões ou critérios universais (neutros) para a resolução das controvérsias científicas. Ver Sankey (1999) e Sankey e Hoyningen-Huene (2001). 
cos que o adversário necessita para defender sua posição" (p. 187). ${ }^{20}$ Consequentemente, "a competição entre paradigmas não é o tipo de batalha que possa ser resolvida por meio de provas" (p. 188) - o que significa que as decisões dos cientistas irão depender, em parte, "das técnicas de argumentação persuasiva que são eficazes no interior das comunidades científicas" (p. 128).

Essas - e outras passagens similares - vão gerar críticas e debates acirrados. Para uma parte dos críticos, a proposição de que paradigmas carregam suas próprias ontologias, e que a mudança de paradigma implica uma mudança de concepção de mundo, ao menos no que se refere às entidades que são objeto da prática científica, conduz a uma posição antirrealista inaceitável, uma adesão a alguma modalidade de idealismo ou nominalismo. Já a admissão da ausência de critérios objetivos e universais para ordenar a escolha entre paradigmas vai ser interpretada como o abandono da racionalidade da ciência, um movimento em direção a um relativismo radical. ${ }^{21}$

Ao longo das décadas seguintes à publicação de A Estrutura, Kuhn procurou responder a uma parte das críticas e buscar esclarecer e/ou desenvolver suas posições - basicamente reafirmando suas divergências frente ao Realismo Metafísico, mas distanciando-se do relativismo e enfatizando sua crença na existência de critérios racionais para escolher teorias alternativas. No que se refere ao tópico da descontinuidade ontológica, Kuhn passou a formular a tese da incomensurabilidade em termos linguísticos, propondo que as diferenças entre paradigmas/teorias decorrem essencialmente dos esquemas conceituais a partir dos quais o mundo no qual a prática científica se dá é concebido e investigado (Kuhn, 1983a, 1991a, 1991b). Assim, os praticantes de paradigmas distintos são como falantes de línguas diferentes, em um contexto em que alguns dos conceitos-chave para descrever a realidade e a experiência são intraduzíveis - e é justamente a impossibilidade de tradução de tais conceitos, caracterizados como "categorias taxonômicas" (Kuhn, 1991b, p. 118), que determina então a descontinuidade

$20 \mathrm{Na}$ transição de um paradigma para outro, os cientistas devem modificar "sua concepção da área de estudos, de seus métodos e de seus objetivos" (Kuhn, 1987, p. 116), por isso, "a escolha entre paradigmas em competição demonstra ser a escolha entre modos incompatíveis de vida comunitária" (p. 127).

21 Esta é a interpretação tanto de Popper (1979) quanto de Lakatos (1979). Hoyningen-Huene (2013) oferece uma refutação detalhada desta leitura de Kuhn como abrindo as portas da ciência ao irracionalismo, concluindo que este "não nega a racionalidade do desenvolvimento da ciência, mas apenas uma concepção particular (simplista) da racionalidade, que assume a escolha teórica como governada por um procedimento algorítmico" (p. 375). No mesmo sentido, ver Nickles (2003, p. 155-58). 
nas ontologias de cada tradição teórica. Contudo, tal incomensurabilidade é sempre local, resultando de diferenças parciais ou localizadas nas estruturas lexicais que são constitutivas da realidade a qual cada teoria é aplicada. O resultado é que os cientistas praticam seus ofícios em mundos apenas parcialmente diferentes, de maneira que "o enorme corpo de crenças não afetado pela mudança [teórica] fornece uma base sobre a qual pode repousar a [avaliação da] desejabilidade da mudança" (Kuhn, 1992, p. 142).

Kuhn rejeita, portanto, a noção de uma realidade em si, de um mundo independente da mente e da linguagem, que seria descrito ou representado pelas teorias científicas. Mas esse abandono do Realismo Metafísico não deve ser confundido com uma afirmação de que o mundo ou a realidade sejam construídos pelos praticantes de cada paradigma, no sentido de serem moldados por seus desejos ou interesses. A mudança teórica implica, junto com a adoção de novas categorias taxonômicas, a mudança do mundo no qual a ciência é praticada, mas isso não torna este mundo menos "real". Afinal, "ele fornece o ambiente, o palco para toda a vida individual e social. Ele impõe restrições rígidas a tal vida; a existência continuada depende de uma adaptação a elas" (Kuhn, 1991b, p. 129).22

Já no que se refere à questão da presença - ou não - de critérios racionais para a escolha entre paradigmas, Kuhn vai argumentar que sua posição não é de crítica ou abandono da racionalidade científica, mas de uma alteração na maneira de concebê-la. Em diversas ocasiões, Kuhn procura afastar a interpretação de que a sua abordagem da evolução do conhecimento implica algum tipo de irracionalismo ou relativismo radical - os cientistas, ele afirma, têm boas razões para escolher entre paradigmas alternativos,

$22 \mathrm{Na}$ definição de Putnam (1981, p. 49), O Realismo Metafísico é uma posição filosófica que compreende três ideias: (i) o mundo - a "realidade" - consiste em uma totalidade fixa de objetos, independentes da mente e da linguagem; (ii) existe exatamente uma, e apenas uma, descrição verdadeira de "como o mundo é"; e (iii) a verdade envolve algum tipo de relação de correspondência entre palavras e signos, de um lado, e coisas ou conjunto de coisas, de outro. É importante notar que recusar essa posição não implica necessariamente defender alguma forma de idealismo radical, no qual o mundo é livremente criado por nossas atividades epistêmicas, nem exige o abandono daqueles elementos mínimos de um realismo do senso comum, ou do realismo (com "r" minúsculo) que está implícito em boa parte da prática científica - na crença de que os objetos a serem estudados têm um comportamento independente das hipóteses teóricas que os descrevem, que as observações desse comportamento oferecem uma base objetiva para avaliar a validade de previsões ou explicações, etc. Nas últimas décadas, diversos autores procuraram formular uma versão do realismo que não carregasse a bagagem metafísica contida em expressões como "independentes da mente e da linguagem" ou "descrição única e completa do mundo tal como ele é". Ver, por exemplo, as noções de "realismo interno" (Putnam, 1981, 1987), "atitude ontológica natural" (Fine, 1984), "realismo perspectivista" (Giere, 2006), e "realismo ativo" (Chang, 2012). 
razões que podem de bom grado ser caracterizadas como racionais, mas isso exige uma concepção de racionalidade distinta da que era convencionalmente aceita na filosofia da ciência, seja na tradição positivista ou na abordagem popperiana.

No Posfácio à Estrutura, escrito em 1969, Kuhn vai argumentar que a sua concepção do processo de escolha teórica pressupõe, sim, que as comunidades científicas possuem critérios bem definidos para comparar e avaliar paradigmas alternativos. ${ }^{23} \mathrm{Tal}$ como exposto detalhadamente em Kuhn (1977), os critérios que ele assume como determinantes na escolha teórica compõem uma lista que é convergente com aquelas usualmente assumidas pelas abordagens tradicionais na filosofia da ciência. Os cientistas, argumenta Kuhn, geralmente esperam que as teorias possuam as seguintes características ou virtudes:

i. exatidão, no sentido de que as consequências da teoria, na forma de aplicações ou proposições sobre dados factuais, devem estar em concordância com a experiência e a observação, seja em termos qualitativos ou quantitativos;

ii. consistência, seja interna - nas relações entre os componentes da teoria - seja externa, nas relações com outras teorias correntemente aceitas e aplicadas ao estudo de aspectos relacionados da natureza;

iii. escopo ou longo alcance, no sentido de que as consequências da teoria devem se estender além das observações e/ou subteorias para as quais ela foi originalmente projetada;

iv. simplicidade, mostrando-se capaz de ordenar fenômenos que, na sua ausência, se apresentam como individualmente isolados e confusos; e

v. fecundidade, a capacidade de desvendar novos fenômenos ou relações antes não verificadas entre fenômenos já conhecidos.

A listagem não é - nem há razões para se almejar que seja - exaustiva, e o próprio Kuhn (1979, p. 289) menciona o critério adicional do poder explicativo, ou "dar um sentido causal aos fenômenos" (Kuhn, 1993, p. 331). O decisivo para o autor - e que afasta drasticamente sua concepção da escolha teórica daquela que encontramos nos positivistas ou em Popper - está 23 Ou seja, a incomensurabilidade não implica a incomparabilidade, mas afeta as formas pelas quais as comparações podem ser realizadas, como ficará claro a seguir. 
na forma como tais critérios são interpretados e aplicados pelos cientistas: não como regras metodológicas que, se utilizadas corretamente e com isenção, eventualmente determinam qual a melhor teoria - seja esta a teoria com maior probabilidade de ser verdadeira (positivistas) ou a teoria mais próxima da verdade (Popper). Os critérios propostos atuam, sim, como valores, que guiam e influenciam as escolhas.

Assumir que os critérios da escolha teórica correspondem a uma constelação de valores compartilhados pelas comunidades científicas implica então aceitar como um fato fundamental da prática científica que os indivíduos podem diferir e discordar na interpretação e aplicação de cada critério a um caso concreto - incluindo aí eventuais divergências na avaliação da resolução de trade offs, quando a aplicação simultânea de mais de um critério gera resultados conflitantes. Logo, elementos ditos "subjetivos" - relacionados à experiência prévia na prática científica de cada indivíduo, ou mesmo à sua personalidade (Kuhn, 1989, p. 325) - participam necessariamente do processo de escolha teórica, não sendo meramente distorções localizadas e idealmente elimináveis na implementação de um conjunto de regras metodológicas impessoais, autoaplicáveis e, neste sentido, inteiramente objetivas. Na verdade, Kuhn argumenta que o espaço para a variação individual nas escolhas dos cientistas tem uma funcionalidade positiva para $\mathrm{o}$ progresso da ciência, pois este "requer um processo decisório que permite que homens racionais discordem" (Kuhn, 1989, p. 332) e apostem em novas teorias antes que estas tenham um sucesso demonstrado na resolução de quebra-cabeças e ganhem a aceitação geral. Sem este espaço para a discordância racional, que é negado pela concepção tradicional do método científico como um algoritmo de decisão, a introdução de novas teorias em uma comunidade seria muito mais difícil. ${ }^{24}$

Por outro lado, a constelação de valores compartilhados pelas comunidades científicas tem um papel indispensável na forma como os cientistas jus-

24 A partir do Posfácio incluído na segunda edição de $A$ estrutura..., Kuhn se refere com frequência a "algoritmos neutros para a escolha de uma teoria" (Kuhn, 1987, p. 246), tendo em mente as versões tradicionais do Método Científico, composto de regras a priori e universais que determinariam a escolha teórica com a força de uma demonstração lógica. Este uso específico do termo algoritmo, que também é comum na literatura sobre a obra de Kuhn, não deve ser interpretado como uma crítica ou oposição ao emprego de algoritmos de programação, em programas de computador, para simular processos cognitivos diversos, incluindo processos decisórios. O próprio Kuhn chegou a explorar a possibilidade de desenvolver um programa para simular o processo de aquisição de um paradigma pelos membros de uma comunidade científica (Kuhn, 1987, p. 237-244; Kuhn, 1974, p. 372). 
tificam suas escolhas diante de seus pares. Ainda que existam ambiguidades na aplicação dos valores compartilhados, a sua presença delimita o espaço no qual a argumentação científica se dá, de maneira que a presença de elementos subjetivos ou idiossincráticos nas escolhas individuais não implica que a decisão de adotar uma teoria se torne meramente uma questão de gosto, ou algo que possa ser explicado por uma psicologia das multidões. Para Kuhn, a presença de fatores individuais - e, neste sentido, subjetivos, nas escolhas guiadas - não implica o abandono da racionalidade, dado que

(...) pode sempre exigir-se aos cientistas que expliquem as respectivas escolhas, para exibir as bases de seus juizos. Esses juizos são eminentemente discutiveis, e quem se recusar a discutir o seu próprio juizo não pode esperar ser levado a sério. (...) Se os meus críticos introduzem o termo "subjetivo" num sentido que se opõe a juizo - sugerindo assim que torno a escolha de teorias indiscutivel, uma questão de gosto - enganaram-se seriamente quanto à minha posição. (1977, p. 402-3).

Ao longo das controvérsias teóricas que caracterizam as revoluções científicas, as escolhas podem ser justificadas a partir de avaliações de que a teoria X é mais exata que a teoria $Y$, mais simples, etc., mas se um cientista afirmasse preferir uma teoria que se mostra comparativamente menos exata (ou menos simples, etc.), mas é equivalente à sua concorrente no que se refere às avaliações que são feitas a partir dos demais valores, ele estaria se excluindo do jogo de linguagem da ciência (Kuhn, 1983b). Desse modo, a incomensurabilidade não implica a incomparabilidade dos paradigmas ou teorias, embora implique, sim, a impossibilidade de certo tipo de comparação - aquela oferecida por regras ou algoritmos abstratos, cuja aplicação determina o resultado da comparação com a força de um argumento lógico. Não obstante, o conhecimento científico se desenvolve a partir da operação de um conjunto bem definido de critérios de avaliação de teorias que atuam como valores capazes de guiar as escolhas dos cientistas e que oferecem as bases para a justificação racional de tais escolhas.

Finalmente, se tais valores compartilhados oferecem - junto com o conjunto de conceitos e crenças não alterados pela mudança de paradigma, dado o caráter local da incomensurabilidade semântica - uma base intersubjetiva para a escolha teórica, este ponto de apoio não requer a concepção de um método fora do tempo e da história. Uma característica fundamental dos valores compartilhados é que as formas de aplicá-los e seus pesos relativos mudam com a passagem do tempo, e muitas dessas 
mudanças estão associadas às próprias mudanças de teoria. ${ }^{25}$ Como argumenta Kuhn (1989), a experiência histórica mostra que as mudanças de valores são graduais e mais lentas que a mudança teórica, ocorrendo em geral como uma consequência não intencional da adoção de novas teorias. ${ }^{26}$ Assim, a estabilidade relativa dos valores é preservada e se mostra suficiente para que possam atuar como elemento que baliza e justifica as escolhas teóricas - desse modo, "a existência de um laço retroativo mediante o qual a mudança teórica afeta os valores que conduzem a essa mudança não torna o processo de decisão circular prejudicial em qualquer sentido" (p. 401).

Um desdobramento importante das ambiguidades na aplicação dos valores compartilhados e de sua mudança no tempo histórico é a possibilidade de que a escolha teórica se faça com base em procedimentos e argumentos que evoluem de forma diferenciada em cada disciplina, configurando uma situação de pluralismo metodológico - do ponto de vista diacrônico e sincrônico. A especificação daqueles valores em uma dada disciplina, em um determinando momento do tempo, refletirá assim a história pregressa de escolhas realizadas por seus membros e seus efeitos retroativos sobre a base que guia as escolhas subsequentes. Podemos então perceber que uma das principais contribuições de Kuhn é "o abandono da ideia de ciência como um empreendimento monolítico único, limitado por um método único" (Kuhn, 1992, p. 149). No seu lugar temos uma concepção pluralista da ciência, na qual a racionalidade das escolhas teóricas depende das práticas sociais que emergem dos valores compartilhados pelas comunidades (uma instituição social) e evolui historicamente, sem um ponto de chegada pré-definido. Como resume Giere (1999, p. 4),

A principal lição que extraio de Kuhn e de muitos outros estudiosos da prática científica é que as próprias categorias com as quais a visão Iluminista da ciência foi formulada são inadequadas para capturar a prática real da ciência, tanto

25 Uma mudança drástica da lista de valores não pode ser a priori excluída, mas implicaria uma mudança da ciência tal como esta é entendida hoje. Se eliminarmos completamente a exatidão, diz Kuhn (1989) teremos algo mais parecido com a filosofia; se introduzirmos a utilidade social como um valor central, o resultado será algo mais próximo da engenharia. O conceito de ciência de Kuhn não está baseado, evidentemente, na presença de um Método Científico comum a qualquer disciplina, mas em uma superposição de similaridades entre as disciplinas, que converge para um conjunto genérico de valores compartilhados.

26 O próprio Kuhn (1971) faz uma análise da evolução histórica do conceito de causa no desenvolvimento da Física, mostrando que aquilo que se considera legitimamente uma causa, capaz de ser usada em uma explicação científica, se transforma à medida que as teorias vão mudando. A conclusão é que "novos cânones de explicação nascem com novas teorias de que são, numa extensão considerável, parasitas” (p. 60). 
historicamente como nas suas formas contemporâneas. Conceitos como os de leis da natureza, verdade e racionalidade não são dados, mas sim categorias interpretativas que possuem suas próprias histórias.

\section{Simon e Kuhn: situando a racionalidade no tempo histórico}

Cotejamento das seções anteriores permite discernir um conjunto articulado de similaridades entre as perspectivas de Simon e Kuhn. Ambos os autores reagem e se afastam de concepções de racionalidade que identificam a escolha racional com algum tipo de algoritmo abstrato e universal, no qual o processo de decisão é reduzido a um conjunto de operações lógicas - seja na forma de modelos de racionalidade substantiva (otimização) ou na caracterização de regras metodológicas que determinam a escolha teórica. Como alternativa, ambos procuram oferecer uma noção de racionalidade que seja aplicável a situações decisórias mal estruturadas, no sentido de que os tomadores de decisão não são capazes de deduzir uma única linha de ação a partir dos parâmetros da decisão com os quais inicialmente se defrontam. Essa indeterminação dos processos decisórios envolve os seguintes aspectos:

i. As escolhas são guiadas por um conjunto variado de objetivos, potencialmente conflitantes. As empresas são organizações orientadas pela busca do lucro, mas suas decisões são frequentemente tomadas a partir de variáveis tais como participações de mercado, taxa de crescimento das vendas, indicadores de eficiência produtiva, etc.; por sua vez, os cientistas, ainda que (retoricamente) dedicados à busca da "verdade", avaliam teorias alternativas com base em um leque de critérios, orientados por uma variedade de propriedades das teorias, cuja hierarquização não está definida a priori.

ii. As alternativas em jogo - e as consequências de escolhê-las - são conhecidas de forma imperfeita, ou podem ser percebidas, concebidas e avaliadas de forma distinta por diferentes indivíduos e grupos de indivíduos. Em condições de racionalidade limitada, os agentes farão escolhas que dependem de uma representação específica do problema decisório, de um determinado conjunto de procedimentos de busca, de expectativas sobre um futuro incerto e de níveis de aspiração gerados por um 
histórico de cotejamentos entre decisões e resultados. Na ciência, a escolha de paradigmas e teorias implica um confronto entre diferentes listagens de problemas científicos relevantes, diferentes especificações e aplicações dos valores compartilhados pela comunidade científica e diferentes crenças relativas à natureza do objeto de estudo e das propriedades do mundo fenomenal a este associado.

iii. Existe uma ambiguidade intrínseca nos critérios de escolha que não se apresentam como regras lógicas cuja aplicação independe da identidade - conhecimentos acumulados, subjetividade e história - daquele que toma a decisão. A presença de elementos idiossincráticos na forma como cada organização organiza e efetua decisões, bem como na maneira como cada cientista aplica os critérios oriundos de valores compartilhados, é encarada como uma propriedade funcional para a dinâmica evolucionária que caracteriza a operação das organizações/mercados (Simon) e da ciência (Kuhn), a qual exige uma variedade comportamental na tomada de decisões.

iv. Ao longo do tempo, tanto a base de conhecimento a partir da qual emergem as alternativas quanto os critérios que guiam as decisões mudam e evoluem, em parte como resultado das próprias decisões - não é possível identificar um conjunto fixo de regras ou procedimentos de decisão racionais, que sejam universalmente válidos.

O resultado é que, seja reconhecido explicitamente (Kuhn) ou não (Simon), temos um processo de escolha no qual os agentes envolvidos se defrontam com alternativas que, por diferentes razões, são incomensuráveis, mas não incomparáveis. A constatação da impossibilidade de aplicar um padrão de medida universal capaz de gerar uma ordenação única das alternativas, que seja independente do contexto e das características dos sujeitos que tomam as decisões, leva esses autores a proporem noções de racionalidade nas quais (i) o caráter racional das escolhas está assentado em um conjunto de atividades e práticas sociais com características específicas, e (ii) tal conjunto evolui no tempo histórico, o que significa uma contínua mudança do conteúdo daqueles procedimentos de decisão ao qual a qualificação de racional se aplica. ${ }^{27}$

27 É claro que tanto a noção de um método científico universal e a priori como o cálculo maximizador da racionalidade substantiva são compatíveis com o reconhecimento de que a tomada racional de decisões depende de um conjunto de instituições e práticas sociais, no sentido de que apenas em determinados contextos sociais as regras abstratas da racionalidade corresponderiam a práticas sociais concretas. O ponto aqui é que, seja na tradição positivista 
O conceito de racionalidade deixa, assim, de estar associado a uma teoria formal e abstrata, que se mostre capaz de identificar as condições necessárias e suficientes para caracterizar uma crença, decisão ou comportamento como racional, estabelecendo regras ou cânones da conduta racional que sejam aplicáveis a toda e qualquer situação concebível. Alternativamente, o conceito de racionalidade passa a ser construído a partir da descrição de práticas sociais situadas na história que permitem formular exemplos e modelos de conduta racional em situações específicas, produzindo generalizações a serem revistas e corrigidas ao serem confrontadas com as condutas efetivas dos agentes. ${ }^{28}$ Para Kuhn, a racionalidade da ciência resulta da aplicação dos valores compartilhados pelas comunidades de cientistas e a forma de fazê-lo muda ao longo do tempo - os critérios de escolha de teorias estão assim situados no tempo histórico e não há como justificá-los externamente às tradições científicas nas quais evoluem, assim como a indução não pode ser justificada por um argumento anterior e externo às práticas indutivas da nossa cultura. ${ }^{29}$ Por sua vez, o que caracteriza as decisões como racionais para Simon é se estas são o resultado de procedimentos de decisão "apropriados", colocando assim a questão: como definir a adequação entre os procedimentos de decisão e o problema decisório e quando o parâmetro absoluto da otimização deve ser descartado? A resposta é que os procedimentos em uso são validados por serem o produto de processos adaptativos de aprendizado, ao longo de uma trajetória histórica de decisões.

A racionalidade é, então, situada no tempo histórico de duas maneiras: (i) a caracterização de escolhas como racionais pressupõe condições contextuais locais e que incluem a sequência histórica das decisões passadas

ou na teoria da escolha racional neoclássica, essas práticas e instituições afetam apenas a forma específica como a conduta racional se manifesta na história humana, mas a racionalidade continua a ser definida, analisada e justificada a partir de um modelo de decisão abstrato e a-histórico.

28 Diante de suas respectivas audiências, Simon e Kuhn convocam seus pares a empreender uma investigação empírica das práticas sociais concretas nas quais a racionalidade está incrustada - seja por meio do recurso à história da ciência, seja pela observação direta dos processos decisórios de indivíduos e organizações.

29 Pode-se aqui fazer um paralelo com a discussão do problema da indução no texto clássico de Nelson Goodman (1983). Goodman se propõe justamente a demonstrar a impossibilidade de uma teoria formal da indução, ou seja, de um conjunto de regras abstratas que determinem a priori a forma das inferências indutivas válidas. Diante disso, ele remete a validação da indução à história das projeções indutivas na cultura, de onde emerge a distinção entre predicados projetáveis (por exemplo, green) e não projetáveis (grue, no conhecido "paradoxo" por ele analisado). 
dos agentes envolvidos - é apenas contra este pano de fundo, no qual estão impressas as decisões anteriormente tomadas, que a racionalidade pode ser delineada; e (ii) os procedimentos e critérios de decisão racionais não possuem uma essência abstrata e imutável, mas mudam como resultado da própria atividade decisória dos indivíduos e grupos de indivíduos, sendo eles próprios parte de um processo evolucionário de aprendizado. Uma lição a ser extraída de Simon e Kuhn é a necessidade de reconhecer o amplo escopo das variedades de comportamento racional a serem analisadas teórica e empiricamente, ao invés de limitar o foco da pesquisa ao refinamento e aplicação de um pequeno conjunto de algoritmos de decisão. Ainda que tais algoritmos sejam aplicáveis com sucesso em um subconjunto de situações, como é o caso de algoritmos de otimização em decisões repetidas em um ambiente pouco complexo e estável, uma abertura a manifestações diferentes da racionalidade humana é fundamental para que as ciências sociais consigam dar a devida atenção aos mecanismos de aprendizado (racional) que são parte decisiva de muitos processos de transformação econômica e social. ${ }^{30}$

\section{Simon e Kuhn: divergências}

Contudo, a identificação de similaridades entre os dois autores não deve levar a uma desconsideração da presença de diferenças fundamentais entre suas abordagens. Uma primeira fonte de tais diferenças está em um aspecto específico - e distintivo - da racionalidade científica, a exigência de que a escolha de uma teoria seja acompanhada pela possibilidade de justificá-la de forma racional. Para Kuhn, os critérios de escolha que emergem dos valores compartilhados nas comunidades científicas não permitem a identificação da melhor teoria com a força de uma demonstração lógica, nem excluem a influência de fatores individuais e subjetivos no processo de escolha - contudo, são suficientes para estabelecer uma base intersubjetiva sobre a qual argumentos podem ser construídos e justificativas podem ser articuladas. Os cientistas devem convencer seus pares de que uma mudan30 É claro que escolher a melhor alterativa existente quando é possível definir um único objetivo e ter um conhecimento extensivo das alternativas, é parte do que se entende por escolher racionalmente - mas apenas parte, e não a essência definidora do conceito. Uma incapacidade de entender a racionalidade como abarcando bem mais que escolhas maximizadoras é uma séria limitação para as ciências sociais, e para a ciência econômica em particular. 
ça teórica é necessária e, por mais que a retórica que leva a tal convencimento tenha elementos subjetivos, os valores compartilhados criam base sobre a qual justificativas racionais são construídas e debatidas. ${ }^{31}$

Em suma, a racionalidade científica tem uma dimensão comunicativa, que se caracteriza pela busca de "um acordo ou consenso, baseado em princípios mutuamente aceitáveis de argumentação e raciocínio, compartilhados por todas as partes em uma disputa" (Friedman, 2001, p. 55). Embora haja controvérsias em relação ao efetivo sucesso de Kuhn em enfrentar essa questão, não há como negar que uma função que este imputa aos valores compartilhados é estabelecer parâmetros dentro dos quais tais justificativas podem ser produzidas e, eventualmente, produzir consensos na comunidade científica relevante. ${ }^{32}$ Nas decisões que são o objeto usual da abordagem de Simon, esta dimensão comunicativa se mostra ausente, ou se apresenta como um aspecto secundário do processo decisório.

Este fato tem implicações relevantes para tentativas de aplicar a teoria da racionalidade procedimental às escolhas dos cientistas. É o caso de De Langhe (2012, 2013), que analisa o problema kuhniano da escolha entre paradigmas alternativos a partir da hipótese de que os cientistas empregam procedimentos de decisão baseados em mecanismos de satisficing, adotando a primeira alternativa teórica que supera certos limites mínimos fixados por critérios de avaliação pré-definidos. A mudança teórica pode, então, ser concebida como um processo dinâmico que é o resultado agregado da interação das decisões individuais, marcado pela presença de dependência de caminho e análogo ao processo de difusão de padrões tecnológicos. Ao

31 A seguinte passagem de Kuhn (1983b, p. 263) é esclarecedora: "racionalidade' e 'justificação' são termos interdefinidos. Um requisito para qualquer deles é a conformidade às restrições da lógica, e tenho feito uso disso para mostrar que as normas usuais para a escolha de teorias estão justificadas ('racionalmente justificadas' seria redundante). Outro requisito é a conformidade às restrições da experiência, na ausência de boas razões em contrário. Ambos exibem parte do que é ser racional".

32 Um ponto a ser debatido é se é possível - e necessário - distinguir valores que seriam efetivamente epistêmicos e poderiam ser caracterizados como parte dos objetivos do próprio empreendimento científico, como a acurácia preditiva e o poder explicativo, de valores que seriam apenas instrumentais, no sentido de se apresentarem apenas como meios para selecionar teorias que satisfaçam aqueles objetivos, como - possivelmente - a coerência e o poder unificador. O tema é objeto dos comentários de McMullin (1993, p. 66-80), que são respondidos por Kuhn (1993, p. 337-339). Ver também as críticas mais extensas de Friedman (2001, 45-57), para quem Kuhn não é bem sucedido em defender a racionalidade científica frente a ataques relativistas, em parte por não distinguir satisfatoriamente os aspectos instrumental e comunicativo da racionalidade humana. 
longo do tempo, as escolhas dos cientistas a cada momento são afetadas pelas escolhas passadas e um paradigma se torna mais atrativo na medida em que vai sendo adotado por um número crescente de cientistas, por três razões (De Langhe, 2012, p. 26):

i. o paradigma que atrai mais cientistas se desenvolve mais rapidamente (efeito aprendizado);

ii. as diferentes contribuições dos cientistas a um determinado paradigma se reforçam mutuamente (efeito escala);

iii. o custo marginal de desenvolver o paradigma diminui com a expansão do número de cientistas que o adotam (externalidades de rede).

A proposta de De Langhe gera insights interessantes, com desdobramentos que merecem ser explorados. Por exemplo, a analogia com a difusão de padrões tecnológicos sugere que as comunidades científicas podem sofrer uma espécie de lock in em paradigmas longamente estabelecidos, ou ainda terem dificuldades em preservar um ambiente de diversidade e pluralismo teórico - uma preocupação frequentemente manifestada por economistas heterodoxos. Contudo, quando a racionalidade científica é reduzida a uma avaliação puramente pragmática - ou seja, instrumental - do desempenho das teorias, perde-se de vista uma de suas características centrais, a formação de consensos a partir do engajamento dos cientistas em processos argumentativos ou comunicativos. A predominância de uma solução tecnológica pode ser o resultado agregado de decisões individuais, nas quais cada agente opta isoladamente por adotá-la a partir de uma avaliação de custos e benefícios; já o sucesso de uma teoria resulta dos processos que envolvem a avaliação de seu desempenho em termos de variáveis instrumentais - aspectos específicos na prática de resolução de quebra-cabeças da comunidade específica que a utiliza - e das estratégicas retóricas e argumentativas dos cientistas, aplicadas em esforços de convencimento de seus pares. Em uma economia de mercado, a decisão de adoção de uma tecnologia cabe às firmas, sendo tomada de forma autônoma em um ambiente competitivo. Na ciência, ainda que existam relações competitivas entre os cientistas, as escolhas teóricas são tomadas em uma coletividade, no qual a difusão de cada teoria é o resultado de esforços cooperativos de convencimento. Para dar conta desses aspectos da dinâmica de evolução do conhecimento científico, é necessário um tratamento das estratégias argumentativas e persuasivas dos cientistas, uma tarefa para 
a qual a teoria da racionalidade procedimental não tem o que oferecer.

Uma segunda fonte de diferenças relevantes pode ser localizada na posição central da incomensurabilidade semântica na abordagem de Kuhn, que não encontra contrapartida na teoria da racionalidade procedimental. É verdade que Simon dá grande importância aos processos pelo qual os agentes constroem representações do ambiente em que atuam, a partir dos quais as alternativas de ação são identificadas e avaliadas. ${ }^{33}$ Isso faz com que as decisões dependam da maneira como cada agente percebe e interpreta o ambiente em que atua, e não de um conjunto de variáveis ambientais dadas e exógenas, mas a construção de tais representações envolve basicamente mecanismos de seleção e processamento de informações - cuja existência é pressuposta como independente de cada representação em particular. Já em Kuhn, o que encontramos é um abandono da noção de uma natureza dada e independente dos paradigmas - o mundo em que os cientistas praticam seus ofícios é, em parte, constituído pelas teorias, ou seja, não é independente dos conceitos e crenças da comunidade que nele trabalha. ${ }^{34}$

A distância entre as duas abordagens fica patente nas aplicações da teoria da racionalidade procedimental ao processo de descoberta de novas teorias científicas - discutida, por exemplo, em Simon (1983) e (1986). ${ }^{35}$

33 Como bem caracteriza Sbicca (2014), nos modelos de decisão de Simon "a apreensão da realidade é um processo ativo de edição" (p. 600), durante o qual informações são selecionadas, omitidas ou distorcidas.

34 Como Kuhn (1991a, p. 268) ironicamente observa:

"Em resumo, acredito realmente em alguns dos absurdos a mim atribuídos - embora de modo algum em todos. Os céus dos gregos eram irredutivelmente diferentes dos nossos. A natureza da diferença é a mesma que Taylor tão brilhantemente descreve entre as práticas sociais de diferentes culturas. Em ambos os casos, a diferença está arraigada em um vocabulário conceitual. Ela não pode ser resolvida por meio de uma descrição num vocabulário de dados brutos, comportamental. (...) Isso não significa que não se possam, com suficiente paciência e esforço, descobrir as categorias de uma outra cultura ou de um estágio anterior da nossa própria cultura. Mas indica, sim, que é necessária uma descoberta e que a interpretação hermenêutica - quer pelo antropólogo, quer pelo historiador - é o que promove tal descoberta. Não existe, nas ciências naturais, não mais do que nas humanas, um conjunto de categorias que seja neutro, independente de cultura, e no qual a população - seja de objetos, seja de ações - possa ser descrita".

35 Para Simon (1977, p. 286), uma teoria da descoberta científica deve ser capaz de identificar os processos que explicam o montante e direção do progresso científico efetivamente observado. Não se trata propriamente de uma teoria da invenção de novas teorias, em contraposição a uma teoria da escolha de teorias, mas sim uma abordagem que concebe a "descoberta" como um processo de resolução de problemas por tentativa e erro, governado por procedimento de busca e de seleção (escolha) de alternativas consideradas satisfatórias. Os modelos de descoberta científica de Simon e seus seguidores têm sofrido críticas no sentido de que (i) seriam "modelos whiggish", pois o problema a ser resolvido está programado nos modelos desde o início, (ii) pressupõem um conjunto de dados observacionais muito simplificado e 
A partir do final dos anos sessenta, Simon desenvolveu modelos que permitem analisar a emergência de novas hipóteses e teorias como o resultado da aplicação de procedimentos de busca heurística, com base em uma representação do problema a ser resolvido e um conjunto de dados observacionais. A premissa é que os cientistas usam regras heurísticas para explorar o universo, aplicando-as sobre um conjunto selecionado de dados observacionais, em um processo de tentativa e erro que não pode ser caracterizado como ótimo - então, "os processos de descoberta são essencialmente os mesmos processos que observamos quando em outras formas de resolução de problemas" (Simon, 1986, p. 13). ${ }^{36}$ Embora Simon reconheça que tais processos dependam fundamentalmente do surgimento de novas representações de problemas, ele acaba por concluir que o repertório de representações é relativamente limitado e que os cientistas podem selecionar entre alternativas já existentes, que fazem parte de uma longa tradição que se estenderia até a Grécia Clássica. ${ }^{37}$

Mesmo sem fazer uma discussão aprofundada dos modelos desenvolvidos por Simon e seus colaboradores, duas divergências em relação a Kuhn são imediatamente visíveis. De um lado, sua descrição da prática científica trata a mudança teórica assumindo implicitamente o pressuposto de que não há uma diferença metodológica relevante entre mudanças de natureza mais incremental e mudanças que implicam um significativo rearranjo de crenças e conceitos fundamentais. Isso não significa que a abordagem de Simon seja, em princípio, inaplicável a grandes mudanças teóricas, mas esta aplicação geraria uma interpretação da história da ciência distinta da que resulta da abordagem kuhniana. Nesta última, é central a distinção entre a ciência normal e as revoluções científicas, entre a mudança teórica dentro de uma dada estrutura conceitual e a mudança da estrutura - o segundo tipo de mudanças altera o mundo fenomenal no qual os cientistas operam, enquanto os modelos de Simon pressupõem que os cientistas não dispõem de um aparato cognitivo capaz de utilizar o conjunto completo sem ruídos, e (iii) não se mostram capazes de captar o contexto confuso e indeterminado que caracteriza os momentos históricos de inovação teórica (Nickles, 2008, p. 445).

36 A prática dos cientistas é racional, "não no sentido de que é um comportamento ótimo, mas no sentido de que é frequentemente bem sucedida em atingir o seu objetivo de descobrir novas teorias. Ela é satisfatória." (Simon, 1986, p. 2).

37 Ver também Simon (1977, p 300-2), no qual o autor contrasta sua abordagem com a descrição de Kuhn das revoluções científicas. Simon destaca que "nós não devemos superestimar a capacidade da mente humana inventar novas representações. O número de tais invenções na história humana é relativamente pequena" (p. 301). 
de dados observacionais disponíveis, mas preserva a noção de um mundo independente dos conceitos que são usados para descrevê-lo, de forma consistente com o Realismo Metafísico. ${ }^{38}$ Para Kuhn, as mudanças teóricas podem - nas revoluções científicas - implicar descontinuidades ontológicas e a análise de tais mudanças evidencia a necessidade de abandonar o Realismo Metafísico, recusando a ideia de que se possa assumir a presença de um mundo fenomenal - e mesmo uma estrutura da realidade - que seja independente dos paradigmas e teorias. Isso não significa que a abordagem de Simon seja inaplicável a grandes mudanças teóricas, mas sim que os resultados obtidos seriam certamente diferentes daqueles expostos na narrativa kuhniana da história da ciência. ${ }^{39}$

Utilizando uma analogia biológica, Kuhn (1991b, 1992) argumenta que, assim como um nicho ecológico não existe independentemente da comunidade de organismos a ela adaptada, o mundo no qual os cientistas exercem sua prática não pode ser concebido como existindo independentemente dos esquemas conceituais e das representações mentais da comunidade que atuam sobre ele. Deste modo,

(...) o que substitui o único e grande mundo sobre o qual os cientistas descobriam a verdade é a variedade de nichos nos quais os praticantes dessas várias especialidades praticam seu oficio. Esses nichos, que criam as ferramentas conceituais e instrumentais com as quais seus habitantes agem sobre eles - tanto quanto são criados pelas mesmas ferramentas -, são tão sólidos, reais e resistentes a mudanças arbitrárias quanto já se disse ser o mundo exterior. Todavia, ao contrário do chamado mundo exterior, não são independentes da mente e da cultura, e não se reduzem a um único todo coerente do qual nós e os praticantes de todas as especialidades científicas individuais somos praticantes. (Kuhn, 1992, p. 150-151).40

38 Esta diferença entre os autores - no que se refere a concepção ou não de dois processos de mudança teórica distintos - é reconhecida pelo próprio Simon (1977, p. 288), ao destacar que sua discussão da descoberta científica "se assenta na hipótese de que não há diferenças qualitativas entre os processos da ciência revolucionária e na ciência normal".

39 Também não implica que o desenvolvimento de modelos baseados da racionalidade procedimental não possa incorporar, em algum grau, processos cognitivos que envolvem alterações no aparato conceitual que os agentes utilizam para descrever o seu ambiente e delinear problemas decisórios, como aponto mais adiante.

40 O repúdio de Kuhn ao Realismo Metafísico é compatível com uma possível adesão a formas mais brandas de realismo que sejam compatíveis com o pluralismo conceitual. Nesta direção, Hoyningen-Huene (1993) apresenta uma interpretação neokantiana da posição de Kuhn, na qual os cientistas vivem e trabalham em um mundo fenomenal, cujo processo de constituição recebe contribuições do "lado-do-sujeito" (conceitos, vocabulário teórico) e contribuições do "lado-do-objeto" (o mundo-em-si, diretamente incognoscível). O desenvolvimento da ciência - especialmente através das revoluções científicas - gera, então, uma pluralidade de mundos fenomenais, sujeitos às resistências que emanam do lado-do-objeto. Mais recentemente, Giere (2013) sugere que Kuhn pode ser interpretado como aderindo a um "realismo perspectivo", que sinteticamente pode ser caracterizado por duas proposições: 
Reconhecer este ponto de afastamento entre os autores implica aceitar limites não só na tentativa de construir um efetivo espaço de convergência entre Simon e Kuhn, mas também na formulação de analogias entre a escolha de paradigmas alternativos e a problemática das decisões sob incerteza na teoria econômica heterodoxa, como faz Cunha (2005). Quando os economistas discutem as decisões dos agentes econômicos, em geral o fazem a partir de um esquema conceitual que é usado tanto na descrição das crenças de cada agente e da situação decisória em que estes se encontram quanto na descrição do ambiente econômico mais geral é justamente da contraposição destas descrições do agente/situação decisória e do ambiente que podem ser extraídas conclusões acerca da impossibilidade de escolher a alternativa ótima em condições de incerteza. Já o problema colocado por Kuhn é outro: a incomensurabilidade dos paradigmas não decorre de dificuldades em conhecer o mundo "como o mundo é", de ter acesso às observações necessárias para proceder à escolha, em suma, de uma incompletude de informação - a incomensurabilidade resulta de uma posição filosófica na qual a realidade é sempre interna aos paradigmas e conjuntos de crenças da comunidade, do abandono do Realismo Metafísico. ${ }^{41}$

Um paralelo mais interessante e promissor com a versão kunhiana de pluralismo conceitual pode ser encontrado na literatura que enfatiza não apenas a ausência de informação decorrente da incerteza, mas a possibilidade de que as concepções da realidade dos agentes - seus modelos mentais - afetem suas decisões e ações. O tema tem sido discutido por autores

(i) as asserções geradas pela prática científica se referem a um mundo real, e não meramente a crenças sobre o mundo, e (ii) estas asserções são sempre relativas a uma perspectiva, a um conjunto de conceitos criados pelos homens, e é dentro dessa perspectiva que proposições potencialmente verdadeiras podem ser formuladas.

41 O que não significa propor que o conhecimento científico se desenvolve sem que o "real" imponha restrições às crenças e práticas dos cientistas, de forma independente de sua vontade e, neste sentido, objetiva. Como apontado logo nas primeiras páginas de $A$ estrutura..., "a observação e a experiência podem e devem restringir drasticamente a extensão das crenças admissíveis, porque de outro modo não haveria ciência" (Kuhn, 1987, p. 23). O mesmo ponto é destacado no último texto por ele publicado em vida, no qual é feita uma crítica de versões radicais do construtivismo, que desconsideram "o modo pelo o qual a natureza entra nas negociações que produzem crenças a seu respeito" (Kuhn, 1992, p. 139). A meu ver, a posição de Kuhn é convergente com o que Chang (2012) denomina de "realismo ativo", que parte de uma definição operacional da "realidade": a realidade externa é tudo aquilo que não é sujeito às nossas vontades. Isso significa assumir que o "mundo real" está "lá fora", restringindo nossas atividades epistêmicas, ainda que não seja independente da mente e da linguagem, ou passível de ser englobado por - ou reduzido a - uma descrição única e completa, uma descrição verdadeira em termos absolutos. 
que enfatizam a dimensão ou função cognitiva das instituições (Scott, 1995; Dequech, 2006) na medida em que elas contêm as "regras que estabelecem [para os atores relevantes] a natureza da realidade e as estruturas através das quais os significados são produzidos" (Scott, 1995, p. 40), ou seja, os sistemas de símbolos, representações, crenças e categorias que constroem as diferentes maneiras pelas quais os agentes percebem e interpretam o mundo natural e social, identificam e classificam suas partes constitutivas, concebem as linhas de ação possíveis e executam as atividades a estas associadas. Mas ainda há muito que avançar na investigação, tanto teórica quanto empírica, de como as categorias e "modelos do mundo" dos agentes influenciam as percepções e representações a partir das quais alternativas de comportamento são descobertas e decisões são tomadas (Dosi et al., 2005). Um tratamento mais aprofundado das estruturas cognitivas dos tomadores de decisão, composta por conceitos, modelos mentais e teorias, deve reconhecer a distinção entre o aprendizado que gera um acúmulo de conhecimento dada esta estrutura e o aprendizado que expande o conhecimento a partir da sua transformação (North, 2005; Nelson, 2008). ${ }^{42}$

\section{Comentário final}

O que significa caracterizar uma crença, uma decisão ou um comportamento como racional? Essa questão tem se mostrado central e controversa tanto na filosofia da ciência quanto nas ciências sociais. A discussão aqui realizada não autoriza concluir que Simon e Kuhn oferecem respostas coincidentes ou convergentes a tal indagação, mas sugere que ambos compartilham uma determinada postura diante dela. Trata-se, na verdade, de uma postura compartilhada por outros autores - podemos encontrá-la em filósofos que acompanharam Kuhn no que pode ser denominada uma "virada em direção à história" que se iniciou nos anos sessenta e foi aprofundada nas décadas seguintes; está claramente presente nos esforços de desenvolvimento teórico de críticos à teoria econômica ortodoxa, sejam keynesianos, evolucionários ou institucionalistas.

$42 \mathrm{Na}$ esfera do progresso técnico, tal distinção é feita por Dosi (1982), por meio da diferenciação entre o aprendizado dentro de um paradigma tecnológico e o aprendizado que ocorre quando se dá uma mudança de paradigma. 
Nos autores estudados, tal postura pode ser caracterizada como envolvendo um esforço de retrabalhar o conceito de racionalidade - um deslocamento conceitual que é um movimento ao mesmo tempo crítico e construtivo. O seu aspecto crítico se expressa no repúdio a concepções puramente formais da racionalidade, nas quais as escolhas são caracterizadas como racionais se podem ser reduzidas à aplicação de regras abstratas e externas ao tomador de decisões - tais regras são tomadas como determinando as escolhas, sem a necessidade de se investigar as práticas específicas e a história de cada agente ou grupo social. Na obra de Kuhn, isso se faz com a crítica à filosofia da ciência tradicional; na de Simon, pelo questionamento da noção de racionalidade como otimização de uma função-objetivo bem definida. Por sua vez, o aspecto construtivo se manifesta na tentativa de desenvolver concepções alternativas de racionalidade, nas quais os procedimentos racionais de decisão não podem ser dissociados das práticas sociais de que fazem parte, envolvem uma ampla diversidade de critérios para avaliação e escolha de alternativas, e evoluem no tempo histórico, a partir de processos evolucionários desencadeados pela interação entre as decisões e seus resultados. Neste sentido, Kuhn e Simon realizam um mesmo movimento de reformulação conceitual, na direção de uma concepção de racionalidade social, plural e histórica, a partir da qual se abrem diversos caminhos de investigação acerca da forma como indivíduos e grupos de indivíduos tomam decisões que envolvem alternativas incomensuráveis, em ambientes complexos e sujeitos à mudança endógena.

Do ponto de vista da ciência econômica, a discussão realizada no artigo evidencia como os legados desses autores reforçam determinadas estratégias para o desenvolvimento de modelos de escolha racional alternativos aos oferecidos pela noção de racionalidade substantiva. A primeira delas consiste em um esforço de investigação em torno das bases cognitivas da racionalidade, integrando teoricamente o tratamento dos procedimentos racionais de decisão e das estruturas cognitivas - por exemplo, conceitos, modelos mentais - a partir dos quais os agentes decidem e aprendem em um ambiente em transformação. A segunda envolve o reconhecimento de que os padrões de conduta racionais devem ser teoricamente concebidos não apenas como parâmetros dos processos econômicos e sociais, mas também como o resultado transitório desses processos no tempo histórico, o que exige uma abordagem explicitamente evolucionária. 


\section{Referências}

ABRANTES, P. Naturalizando a epistemologia. In: ABRANTES, Paulo (Org.) Epistemologia e Cognição. Brasília: Editora da UnB, 1993. p. 171-218.

AUGIER, M.; KREINER, K. Rationality, Imagination and Intelligence: Some Boundaries in Human Decision-making. Industrial and Corporate Change, v. 9, n. 4, 2000. p. 659-681.

BARROS, G. Herbert A. Simon and the concept of rationality: Boundaries and procedures, Revista de Economia Política, 30 (3), 2010, p. 455-472.

CHANG, H. Is Water H2O?: Evidence, Realism and Pluralism. New York: Springer, 2012.

CUNHA, F. B. C. Incerteza, racionalidade e escolha: os novos rumos da teoria econômica, Tese de Doutorado, Instituto de Economia/UFRJ, 2005.

DE LANGHE, R. The Problem of Kuhnian Rationality. Philosophica, 86, 2012. p. 12-31.

DE LANGHE, R. Satisficing as an Account of Kuhnian Rationality. Philosophy Study, v. 3, n. 5, 2013. p. 398-411.

DEQUECH, D. Bounded Rationality, Institutions and Uncertainty. Journal of Economic Issues, v. XXXV, n. 4, 1991.

DEQUECH, D. The new institutional economics and the theory of behaviour under uncertainty. Journal of Economic Behavior \& Organization, v. 59, 2006. p. 109-131.

DOSI, G. Technological paradigms and technological trajectories. Research Policy, 11, 1982. p. $147-162$.

DOSI, G. A Very Reasonable Objective Still Beyond Our Reach: Economics as an Empirically Disciplined Social Science. In: AUGIER, M.; MARCH, J. G. (Eds.). Models of a Man: Essays in Memory of Herbert A. Simon. Cambridge: The MIT Press, 2004. p. 211-26.

DOSI, G.; EGIDI, M. Substantive and procedural uncertainty: an exploration of economic behaviours in changing environments. Journal of Evolutionary Economics, 1, 1991. p. 145-168.

DOSI, G.; MARENGO, L.; FAGGIOLO, G. Learning in Evolutionary Environments. In: DOPFER, K. (Ed.). The Evolutionary Foundations of Economics, Cambridge: Cambridge University Press, 2005 p. 255-338.

FINE, A. The Normal Ontological Attitude. In: LEPLIN, J. (Ed.). Scientific Realism. Berkeley: University of California Press, 1984. pp. 83-107. (Reimpresso em: BOYD, Richard; GASPER, Philip; TROUT, J. D. (Eds.) The Philosophy of Science. Cambridge (Mass.): The MIT Press, 1991).

FRIEDMAN, M. Dynamics of Reason. Stanford: CSLI Publications, 2001.

GIERE, R. N. Explaning Science: a Cognitive Approach. Chicago: The University of Chicago, 1988.

GIERE, R. N. Scientific rationality as instrumental rationality. Studies in History and Philosophy of Science - Part A, v. 20, n. 3, 1989. p. 377-38.

GIERE, R. N. Science without laws. Chicago: University of Chicago Press, 1999.

GIERE, R. N. Scientific perspectivism. Chicago: University of Chicago Press, 2006.

GIERE, R. N. Naturalism. In: PSILLOS, S.; CURD, M. (Eds.), The Routledge Companion to Philosophy of Science. Londres: Routledge, 2008. p. 213-223. 
GIERE, R. N. Kuhn as Perspectival Realist. Topoi, 32, 2013. p. 53-57.

GOODMAN, N. Fact, Fiction and Forecast. Cambridge: Harvard University Press, 1983.

HACKING, I. Representing and Intervening. Cambridge: Cambridge University Press, 1983.

HOYNINGEN-HUENE, P. Reconstructing Scientific Revolutions: Thomas S. Kuhn's Philosophy of Science. Chicago: University Chicago Press, 1993.

HOYNINGEN-HUENE, P. Irrationality in Scientific Development? Philosophy Study, v. 3, n. 5, 2013. p. 367-376.

KEYNES, J. M. The General Theory of Employment, Interest and Money, London: Macmillan, 1936.

KITCHER, P. The naturalists return. The Philosophical Review, v. 101, n. 1, 1992. p. 53-114.

KUHN, T. S. Les notions de causalité dans le developpement de la physique. In: BUNGE, M.; HALBWACHS, F.; KUHN, T. S.; PIAGET, J. Les théories de la causalité. Paris: Presses Universitaires de France, 1971, pp. 7-18. (Reimpresso em KUHN, T. S. A Tensão Essencial. Lisboa: Edições 70, 1989. p 51-62).

KUHN, T. S. Second Thoughts on Paradigms. In: SUPPE, F. (Ed.). The Structure of Scientific Theories. Urbana: University of Illinois Press, 1974, p. 459-62. (Reimpresso em KUHN, T. S. A Tensão Essencial. Lisboa: Edições 70, 1989. p 353-406.)

KUHN, T. S. Reflexões sobre os meus Críticos. In: LAKATOS, I.; MUSGRAVE, A. (Org.). A crítica e o desenvolvimento do conhecimento. São Paulo: Editora Cultrix, 1979. pp. 285-343.

KUHN, T. S. Commensurability, Comparability, Communicability. In: ASQUITH, P. D.; NICKLES, T. (Eds.) PSA 1982: Proceedings of the 1982 Biennial Meeting of the Philosophy of Science Association, v. 2, East Lansing: Philosophy of Science Associations, 1983a, p. 669688. (Reimpresso em KUHN, T. S. O caminho desde A estrutura: ensaios filosóficos 19701993. São Paulo: Editora da UNESP, 2003, p.47-76.)

KUHN, T. S. Rationality and Theory Choice. Journal of Philosophy, v. 80, 1983b, p. 563-570. (Reimpresso em KUHN, T. S. O caminho desde A estrutura: ensaios filosóficos 1970-1993. São Paulo: Editora da UNESP, 2003, p.255-264.)

KUHN, T. S. A estrutura das revoluções científicas. São Paulo: Ed. Perspectiva, 1987.

KUHN, T. S. Objetividade, juízo de valor e escolha teórica. In: KUHN, T. S. A Tensão Essencial. Lisboa: Edições 70, 1989. p. 383-406.

KUHN, T. S. The Natural and the Human Sciences. In: HILEY, D. R.; BOHMAN, J. F. e SHUSTERMAN, R. (Eds.), The Interpretive Turn: Philosophy, Science, Culture. Ithaca: Cornell University Press, 1991a. pp. 17-24. (Reimpresso em KUHN, T. S., O Caminho desde A estrutura: ensaios filosóficos 1970-1993. São Paulo: Editora da UNESP, 2003. p. 265-273.)

KUHN, T. S. The Road since Structure. In: FINE, A.; FORBES, M.; WESSELS, L. PSA 1990: Proceedings of the 1990 Biennial Meeting of the Philosophy of Science Association, v. 2, East Lansing: Philosophy of Science Associations, 1991b, p. 3-13. (Reimpresso em KUHN, T. S. O Caminho desde A estrutura: ensaios filosóficos 1970-1993. São Paulo: Editora da UNESP, 2003. p. 115-132).

KUHN, T. S. The Trouble with the Historical Philosophy of Science. Occasional Publications of the Department of the History of Science. Cambridge: Harvard University Press, 1992. 
(Reimpresso em KUHN, T. S. O Caminho desde A Estrutura: Ensaios Filosóficos 1970-1993. São Paulo: Editora da UNESP, 2003, p.133-151).

KUHN, T. S. Afterwords. In: HORWICH, P. (Ed.) World Changes: Thomas Kuhn and the Nature of Science, Cambridge (Mass.): The MIT Press, 1993. p. 311-341.

LAKATOS, I. O falseamento e a metodologia dos programas de pesquisa científica. In: LAKATOS, I.; MUSGRAVE, A. (Org.) A Crítica e o Desenvolvimento do Conhecimento. São Paulo: Editora Cultrix, 1979. p. 109-243.

LAUDAN, L. Aim-less epistemology. Studies in History and Philosophy of Science - Part A, v. 21, n. 2, 1990. p. 315-22.

LOASBY, B. J. Organization, Competition, and the Growth of Knowledge. In: LANGLOIS, R. N. (Ed.), Economics as a Process: Essays in the New Institutional Economics. Cambridge: Cambridge University Press, 1986. p. 41-57.

LOASBY, B. J. The Mind and the Method of the Economist: a Critical Appraisal of Major Economists in the 20th Century. Aldershot: Edward Elgar, 1987.

McMULLIN, E. Rationality and Paradigm Change in Science In: HORWICH, P. (Ed.). World Changes: Thomas Kuhn and the Nature of Science. Cambridge: The MIT Press, 1993. p. 55-78.

MILLER, K. Simon and Polanyi on Rationality and Knowledge. Organization Studies, 29 (07), 2008. p. 933-955.

NELSON, R. R. Bounded rationality, cognitive maps, and trial and error learning, Journal of Economic Behavior \& Organization, v. 67, n. 1, 2008. p. 78-89.

NELSON, R. R. Human Behavior and Cognition in Evolutionary Economics. Biological Theory, v. 6, n. 4, 2011. p 293-300.

NELSON, R. R.; WINTER, S. An Evolutionary Theory of Economic Change. Cambridge (Mass.): Harvard University Press, 1982.

NICKLES, T. Normal Science: From Logic to Case-Based and Model-Based Reasoning. Thomas Kuhn. Cambridge: Cambridge University Press, 2003. p. 142-177.

NICKLES, T. Scientific Discovery. In: PSILLOS, S.; CURD, M. (Eds.), The Routledge Companion to Philosophy of Science. Londres: Routledge, 2008. p. 442-451.

NORTH, D. C. Institutions and the performance of economies over time. In: MÉNARD, C; SHIRLEY, M. (Eds.) Handbook of New Institutional Economics. Dordrecht: Springer, 2005. p. 21-30.

PUTNAM, H. Reason, Truth and History. Cambridge: Cambridge University Press, 1981.

PUTNAM, H. The Many Faces of Realism. La Salle: Open Court Publishing Company, 1987.

POPPER, K. A ciência normal e seus perigos. In: LAKATOS, I.; MUSGRAVE, A. (Org.) A crítica e o desenvolvimento do conhecimento. São Paulo: Editora Cultrix, 1979. p. 63-71.

POSSAS, M. L. Elementos para uma integração Micro-macrodinâmica na Teoria do Desenvolvimento Econômico. Revista Brasileira de Inovação, v. 1, Ano 1, 2002, p. 123-149.

RIZZELLO, S. Herbert Simon's heritage, CESMEP Working Papers 07/2002, Universitá di Turino. Disponível em: http://www.cesmep.unito.it/WP/7_WP_Cesmep.pdf. Acesso em: 16/04/2014. 
ROUSE, J. Recovering Thomas Kuhn. Topoi, v. 32, n. 1, 2013, p. 59-64.

SANKEY, H. Incommensurability - an overview. Divinatio: Studia culturologica series, 10, 1999 , p. 1-13.

SANKEY, H.; HOYNINGEN-HUENE, P. (Eds.) Introduction. In: Incommensurability and Related Matters. Dordrecht: Kluwer Academic Publishers, 2001, p. vii-xxxiv.

SBICCA, A. Heurísticas no Estudo das Decisões Econômicas: Contribuições de Herbert Simon, Daniel Kahneman e Amos Tversky. Estudos Econômicos, v. 44, n. 3, p.579-603, 2014.

SCOTT, W. R. Institutions and Organizations. Thousand Oaks: SAGE Publications, 1995.

SIMON, H. A. A behavioral model of rational choice. Quartely Journal of Economics, 69, February, 1955, p. 99-118.

SIMON, H. A. Theories of Decision Making in Economics and Behavioral Science. American Economic Review, v. 49, June, 1959, p. 253-258.

SIMON, H. A. From Substantive Rationality to Procedural Rationality, In: HAHN, F.; HOLLIS, M. (Eds.). Philosophy and Economic Theory. Oxford: Oxford University Press, 1976. p. 65-86.

SIMON, H. A. Models of Discovery. Boston: D. Reidel Publishing Company, 1977.

SIMON, H. A. Rationality as Process and as Product of Thought. American Economic Review 68, 1978, p.1-16.

SIMON, H. A. Rational Decision Making in Business Organization. American Economic Review, v. 69, September, 1979, p. 493-513.

SIMON, H. A. Discovery, invention, and development: Human creative thinking, Proc. National Academy of Sciences, v. 80, 1983, p. 4569-4571.

SIMON, H. A. Is scientific discovery a topic in the philosophy of science? Carnnegie Mellon University - Complex Information Processing (CIP), Paper \#456. 1986. Disponível em: http://doi.library.cmu.edu/10.1184/pmc/simon/box00014/fld00954/bdl0001/doc0001. Acesso em: 02/06/2014.

STIGLER, G. J. The Economics of Information. Journal of Political Economy, 69, (3), June, 1961, p. 213-225.

VANBERG, V. Rational Choice, Rule-Following and Institutions: An Evolutionary Approach. In: MÄKI, U.; GUSTAFSSON, B.; KNUDSEN, C. (Eds.), Rationality, Institutions and Economic Methodology. London: Routledge, 1993, p. 171-97.

WINTER, S. Toward a neo-Schumpeterian theory of the firm. Industrial and Corporate Change, 15 (1), 2006, p. 125-141.

WRAY, K. B. Kuhn's evolutionary social epistemology. Cambridge: Cambridge University Press, 2011.

\section{Sobre o autor}

JoãoLuizPondé - ponde@ie.ufrj.br

Instituto de Economia da Universidade Federal do Rio de Janeiro, Rio de janeiro, RJ.

\section{Sobre 0 artigo}

Recebido em 08 de abril de 2015. Aprovado em 18 de agosto de 2016. 